\title{
Serum posaconazole levels among haematological cancer patients taking extended release tablets is affected by body weight and diarrhoea: single centre retrospective analysis
}

\author{
Marisa H. Miceli, ${ }^{1}$ Anthony J. Perissinotti, ${ }^{2}$ Carol A. Kauffman ${ }^{1,3}$ and Daniel R. Couriel ${ }^{4}$ \\ ${ }^{1}$ Division of Infectious Diseases, Department of Internal Medicine, University of Michigan Health System, Ann Arbor, MI, ${ }^{2}$ Department of Pharmacy, \\ University of Michigan Health System, Ann Arbor, MI, ${ }^{3}$ Veterans Affairs Ann Arbor Healthcare System, Ann Arbor, MI and ${ }^{4}$ Division of Hematologyl \\ Oncology, Department of Internal Medicine, University of Michigan Health System, Ann Arbor, MI
}

\section{Summary}

\begin{abstract}
The posaconazole extended release tablet formulation was developed to improve bioavailability relative to the oral suspension. Therapeutic drug monitoring has been used to optimise posaconazole dosing to achieve a target trough level $\geq 0.7 \mu \mathrm{g} \mathrm{ml}^{-1}$. We retrospectively evaluated 28 patients with haematological malignancies who received posaconazole tablets for antifungal prophylaxis. Posaconazole serum trough levels were obtained 5 days after initiation of therapy. Mean trough level was $1.19 \pm 0.63 \mu \mathrm{g} \mathrm{ml}^{-1}$, and $71 \%$ achieved a trough level $\geq 0.7 \mu \mathrm{g} \mathrm{ml}^{-1}$. Diarrhoea was associated with lower mean trough levels $\left(0.65 \pm 0.08 \mu \mathrm{g} \mathrm{ml}^{-1}\right.$ vs. $\left.1.31 \pm 0.13 \mu \mathrm{g} \mathrm{ml}^{-1}\right), \quad P=0.002$. Mean trough levels were lower in patients $\geq 90 \mathrm{~kg}\left(0.74 \pm 0.09 \mu \mathrm{g} \mathrm{ml}^{-1}\right)$ vs. $<90 \mathrm{~kg}\left(1.32 \pm 0.14 \mu \mathrm{g} \mathrm{ml}^{-1}\right), P=0.002$ and in patients with body mass index (BMI) $\geq 30\left(0.89 \pm 0.13 \mu \mathrm{g} \mathrm{ml}^{-1}\right)$ vs. BMI $<30$ $\left(1.29 \pm 0.14 \mu \mathrm{g} \mathrm{ml}^{-1}\right), P=0.05$. Posaconazole delayed release tablets attain appropriate trough levels in most patients, but patients with a higher weight and those experiencing diarrhoea are more likely to have lower levels.
\end{abstract}

Key words: Posaconazole tablets, therapeutic drug monitoring, antifungals.

\section{Introduction}

Patients with acute myeloid leukaemia (AML) and patients undergoing haematopoietic cell transplantation (HCT) are at high risk of developing invasive fungal infections. ${ }^{1,2}$ Early antifungal treatment and prevention are critical to improve survival of these patients. Posaconazole is an antifungal triazole used for prophylaxis in patients with AML and HCT

Correspondence: Marisa H. Miceli, Department of Internal Medicine, Division of Infectious Diseases, University of Michigan Medical School, 3120 Taubman Center, 1500 E. Medical Center Dr. SPC 5378, Ann Arbor, Michigan 48109-5378, USA.

Tel.: (734) 936 3927. Fax: (734) 9362737.

E-mail: mmiceli@med.umich.edu

Submitted for publication 10 November 2014

Revised 2 March 2015

Accepted for publication 24 March 2015 recipients. ${ }^{3,4}$ Use of posaconazole prophylaxis is one of the few interventions that has improved overall survival in AML. ${ }^{3}$ Initially, this agent was available only as a suspension that had rate-limiting absorption, was hampered by inter- and intra-patient pharmacokinetic variability, with a potential for suboptimal trough levels and breakthrough fungal infections. ${ }^{5}$ Furthermore, posaconazole suspension had to be administered with food, which was another practical problem in a patient population with frequent mucositis, nausea and vomiting due to chemotherapy. Thus, therapeutic drug monitoring of posaconazole has become a valuable clinical tool to ensure that optimal drug levels are achieved and efficacy is enhanced.

The Food and Drug Administration has recently approved a delayed release posaconazole tablet formulation that is reported to improve oral bioavailability. The pharmacokinetics and safety of the new formulation is based on healthy volunteer studies. ${ }^{6-8}$ This 
report describes our experience using the delayed release posaconazole tablet for prophylaxis in high-risk patients, with a focus on clinical parameters that may impact serum posaconazole levels, and that could be used as an aid to individualise dosing of this new formulation.

\section{Material and methods}

This is a retrospective chart review study of patients undergoing chemotherapy for AML and HCT recipients who received delayed release posaconazole tablets for prophylaxis from 1 February 2014 through 15 May 2014. Patients were eligible for the study if they received posaconazole tablets at the recommended dose of $300 \mathrm{mg}$ twice daily on day 1 followed by $300 \mathrm{mg}$ daily, and posaconazole steady state serum trough levels were obtained on day 5. Patients were excluded if they were already receiving posaconazole or were being treated with a different dose of posaconazole than that recommended by the package insert. This study was approved by the University of Michigan Healthcare System Institutional Review Board.

Posaconazole serum trough levels were measured using high-performance liquid chromatography assaytandem mass spectrometry (performed at Mayo Clinic Department of Laboratory Medicine and Pathology, Rochester, MN). Therapeutic posaconazole serum trough concentration was defined as $\geq 0.7 \mu \mathrm{g} \mathrm{ml}^{-1}$ as previously suggested for prophylactic antifungal efficacy. ${ }^{9,10}$ Relevant demographics and patient characteristics, including body mass index (BMI) and actual body weight in kilograms, were obtained through chart review. Clinical data, including diarrhoea, oral intake, and concomitant use of proton-pump inhibitors (PPI) or histamine-2 receptor antagonists $\left(\mathrm{H}_{2} \mathrm{RAs}\right)$ were recorded.

Diarrhoea was defined as frequent and watery bowel movement based on the Common Terminology Criteria for Adverse Events definitions (CTCAE version 4.03: any increase of $\geq 4$ stools per day over baseline, faecal incontinence, or moderate to severe increase in ostomy output compared to baseline). ${ }^{11}$

All statistical analyses were performed using GraphPad Software (San Diego, CA). Statistical differences between groups were determined using a Student's $t$ test with Welch's correction and a one-way analysis of variance (ANOVA) with a Turkey's multiple comparison test performed between groups for additional comparisons. Pearson correlation coefficient was calculated to assess the relationship between BMI and posaconazole serum trough levels and between actual body weight and posaconazole serum trough levels. Quantitative variables were reported as the number (percentage) and continuous variables as the mean \pm standard error of the mean (SEM). A value of $P<0.05$ was considered significant.

\section{Results}

A total of 28 patients (22 receiving chemotherapy for AML and $6 \mathrm{HCT}$ recipients) received the recommended dose of posaconazole and had a posaconazole serum trough level drawn on day 5 (Table 1). The day 5 mean serum trough level was $1.19 \pm 0.63 \mu \mathrm{g} \mathrm{ml}^{-1}$ (range: $0.36-2.50 \mu \mathrm{g} \mathrm{ml}^{-1}$ ). Seventy-one percent of the patients achieved the target level of $\geq 0.7 \mu \mathrm{g} \mathrm{ml}^{-1}$.

The effect of concomitant use of proton-pump inhibitors/histamine- 2 receptor antagonists, diarrhoea, oral intake and weight on posaconazole serum trough levels at day 5 are reported in Table 2. Twenty-three of 28 patients were treated with either a PPI or $\mathrm{H}_{2} \mathrm{RAs}$. Mean trough levels among patients receiving these agents was $1.11 \pm 0.12 \mu \mathrm{g} \mathrm{ml}^{-1}$ vs. mean trough levels of $1.62 \pm 0.32 \mu \mathrm{g} \mathrm{ml}^{-1}$ among patients not receiving either of these agents $(P=0.19)$.

Five patients who had diarrhoea documented during the 5 days prior to obtaining the serum trough concentration had mean posaconazole trough level of $0.65 \pm 0.08 \mu \mathrm{g} \mathrm{ml}^{-1}$ compared with a mean of $1.31 \pm 0.13 \mu \mathrm{g} \mathrm{ml}^{-1}$ in patients without diarrhoea $(P=0.002)$. Only 2 of 5 patients $(40 \%)$ with diarrhoea achieved posaconazole trough concentrations $\geq 0.7 \mu \mathrm{g} \mathrm{ml}^{-1}$ compared with 20 of 23 patients $(86 \%)$ who did not have diarrhoea.

Three of twenty-eight patients were fasting during treatment with posaconazole extended release tablets.

Table 1 Patient demographics.

\begin{tabular}{lc}
\hline Demographic characteristics & Patient data \\
\hline Age, year, mean (range) & $53(19-77)$ \\
Male & $16(57 \%)$ \\
Race/ethnicity & \\
Caucasian & $23(82 \%)$ \\
African American & $2(7 \%)$ \\
Hispanic & $2(7 \%)$ \\
Unknown & $1(4 \%)$ \\
Actual body weight, $\mathrm{kg}$ (mean, range) & $79.8(54.7-122.3)$ \\
$<90 \mathrm{~kg}, n(\%)$ & $22(78.5 \%)$ \\
$\geq 90 \mathrm{~kg}, n(\%)$ & $6(21.5 \%)$ \\
Body mass index ${ }^{1}, \mathrm{~kg} / \mathrm{m}^{2}$ (mean, range) & $27(20.4-36.9)$ \\
$<30, n(\%)$ & $21(75 \%)$ \\
$\geq 30, n(\%)$ & $7(25 \%)$ \\
\hline
\end{tabular}

${ }^{1}$ There were no patients with BMI below 20. 
Table 2 Effect of oral intake, concomitant use of proton-pump inhibitors/histamine-2 receptor antagonists, diarrhoea, and weight on posaconazole serum trough levels at day 5 .

\begin{tabular}{|c|c|c|c|c|}
\hline Risk factor & & $\begin{array}{l}\text { Patients, } \\
n(\%)\end{array}$ & $\begin{array}{l}\text { Posaconazole } \\
\text { trough level } \\
\text { (mean } \pm S D \text { ) }\end{array}$ & $P$ value \\
\hline Oral intake & $\begin{array}{l}\text { Yes } \\
\text { No }\end{array}$ & $\begin{array}{c}25(89 \%) \\
3(11 \%)^{1}\end{array}$ & $\begin{array}{l}1.25 \pm 0.13 \mu \mathrm{g} \mathrm{ml}^{-1} \\
0.71 \pm 0.08 \mu \mathrm{g} \mathrm{ml}^{-1}\end{array}$ & - \\
\hline $\begin{array}{l}\text { Concomitant } \\
\text { use of } \\
\text { PPI/H2RA }\end{array}$ & $\begin{array}{l}\text { Yes } \\
\text { No }\end{array}$ & $\begin{array}{r}23(82 \%) \\
5(18 \%)^{3}\end{array}$ & $\begin{array}{l}1.11 \pm 0.12 \mu \mathrm{g} \mathrm{ml}^{-1} \\
1.62 \pm 0.32 \mu \mathrm{g} \mathrm{ml}^{-1}\end{array}$ & NS \\
\hline Diarrhoea & $\begin{array}{l}\text { Yes } \\
\text { No }\end{array}$ & $\begin{array}{r}5(82 \%) \\
23(18 \%)\end{array}$ & $\begin{array}{l}0.65 \pm 0.08 \mu \mathrm{g} \mathrm{ml}^{-1} \\
1.31 \pm 0.13 \mu \mathrm{g} \mathrm{ml}^{-1}\end{array}$ & 0.002 \\
\hline $\mathrm{BMI}^{4}$ & $\begin{array}{l}<30 \\
\geq 30\end{array}$ & $\begin{array}{r}21(75 \%) \\
7(25 \%)\end{array}$ & $\begin{array}{l}1.29 \pm 0.14 \mu \mathrm{g} \mathrm{ml}^{-1} \\
0.89 \pm 0.13 \mu \mathrm{gl}^{-1}\end{array}$ & 0.05 \\
\hline $\begin{array}{l}\text { Actual body } \\
\text { weight }(\mathrm{kg})^{4}\end{array}$ & $\begin{array}{l}<90 \\
\geq 90\end{array}$ & $\begin{array}{r}22(78 \%) \\
6(22 \%)\end{array}$ & $\begin{array}{l}1.32 \pm 0.14 \mu \mathrm{g} \mathrm{ml}^{-1} \\
0.74 \pm 0.09 \mu \mathrm{g} \mathrm{ml}^{-1}\end{array}$ & 0.002 \\
\hline
\end{tabular}

${ }^{1}$ All three patients had diarrhoea, no further analysis was possible after excluding these patients.

${ }^{2} \mathrm{PPI} / \mathrm{H} 2 \mathrm{RA}$, proton-pump inhibitors/histamine-2 receptor antagonists.

${ }^{3}$ Only one of five patients who did not receive PPI/H2RA had diarrhoea, posaconazole trough level for that patient was $0.84 \mu \mathrm{g} \mathrm{ml}^{-1}$.

${ }^{4}$ After excluding patients with diarrhoea, patient weight and BMI affected posaconazole levels significantly (see Fig. 1b).
Posaconazole serum trough levels for these patients were $0.72,0.84$ and $0.57 \mu \mathrm{g} \mathrm{ml}^{-1}$; the last two patients also had diarrhoea. The remaining 25 patients were not fasting and received posaconazole without regard to food, achieving mean posaconazole serum trough levels of $1.25 \pm 0.13 \mu \mathrm{g} \mathrm{ml}^{-1}$. Three of these 25 patients also had diarrhoea; posaconazole trough levels were $0.4, \quad 0.68$ and $0.76 \mu \mathrm{g} \mathrm{ml}^{-1}$ respectively.

We evaluated the effect of weight on posaconazole trough concentration levels of all 28 patients included in the study. We observed that mean posaconazole trough concentrations were lower in patients who weighed $\geq 90 \mathrm{~kg}\left(0.74 \pm 0.09 \mu \mathrm{g} \mathrm{ml}^{-1}\right)$ compared with those who weighed $<90 \mathrm{~kg}\left(1.32 \pm 0.14 \mu \mathrm{g} \mathrm{ml}^{-1}\right)$ $(P=0.002)$. Similarly, mean posaconazole trough levels were lower in patients with $\mathrm{BMI} \geq 30$ $\left(0.89 \pm 0.13 \mu \mathrm{g} \mathrm{ml}^{-1}\right) \quad$ compared with $\quad$ BMI $<30$ (1.29 $\left.\pm 0.14 \mu \mathrm{g} \mathrm{ml}^{-1}\right), P=0.05$ (Fig. 1a).

Because of the effect of diarrhoea on posaconazole trough levels noted above, we conducted a separate analysis of the effect of weight on posaconazole trough levels in the 23 patients who did not have diarrhoea. Patients who weighed $\geq 90 \mathrm{~kg}$ had lower posaconazole trough levels (mean $0.75 \pm 0.14 \mu \mathrm{g} \mathrm{ml}^{-1}$ ) compared
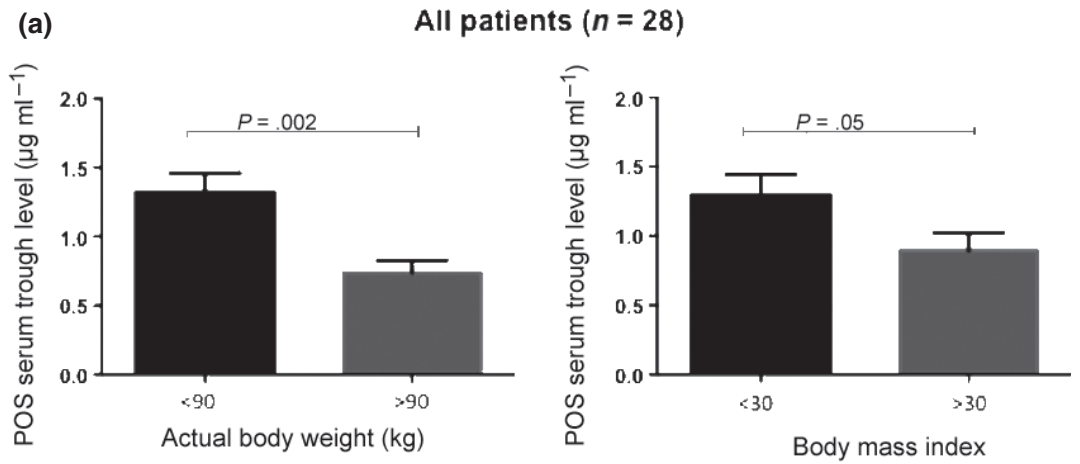
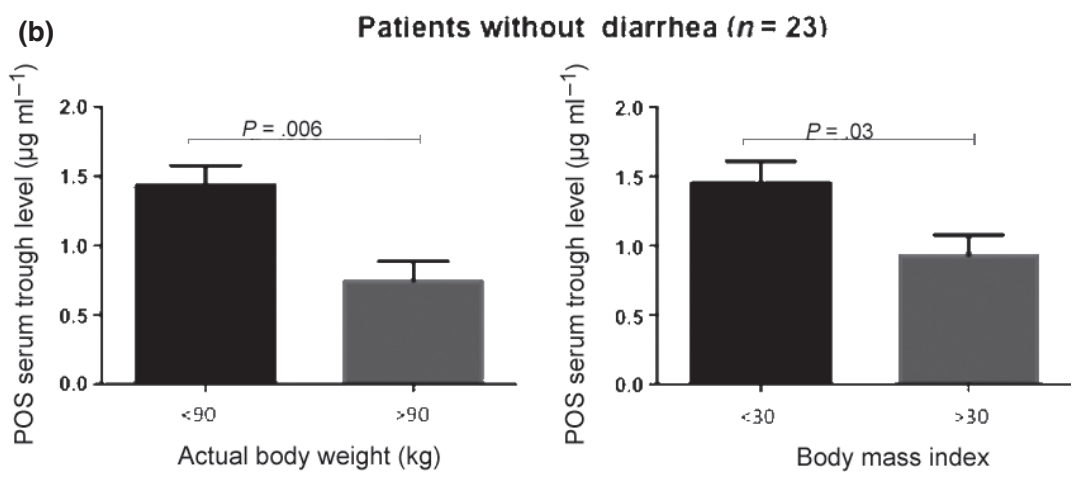

Figure 1 Effect of body mass index and actual body weight on posaconazole serum trough level. (a) Distribution of mean posaconazole serum trough levels in all 28 patients based on actual body weight ( $<90$ vs. $\geq 90 \mathrm{~kg}$ ) and body mass index (<30 vs. $\geq 30$ ). (b) Distribution of mean posaconazole serum trough levels when five patients who had diarrhoea were excluded from the analysis. Patients are divided based on actual body weight $(<90$ vs. $\geq 90 \mathrm{~kg})$ and body mass index (<30 vs. $\geq 30$ ). 
Figure 2 Correlation between body mass index/actual body weight and posaconazole serum trough level. (a) Distribution of actual body weight and body mass index in all 28 patients and its correlation with posaconazole serum trough levels. (b) Distribution of actual body weight and body mass index and the correlation with posaconazole serum trough levels, after excluding the five patients who had diarrhoea.
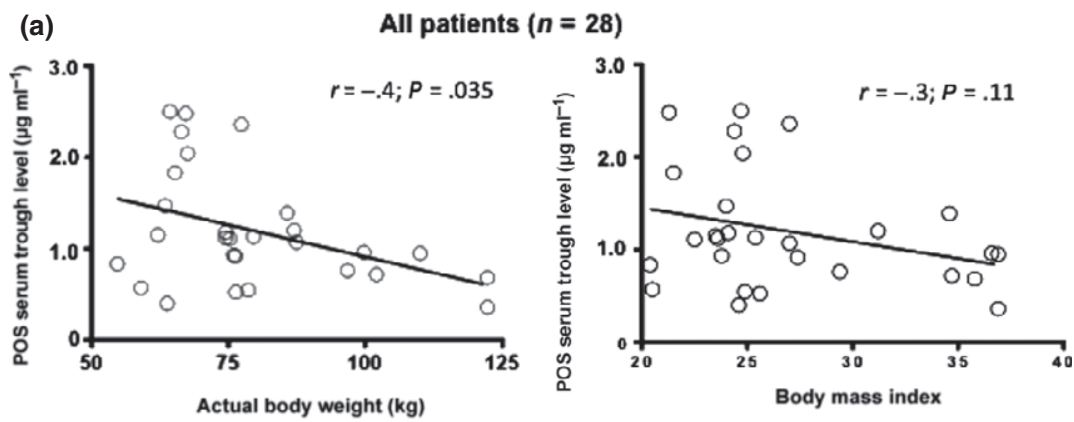

(b)
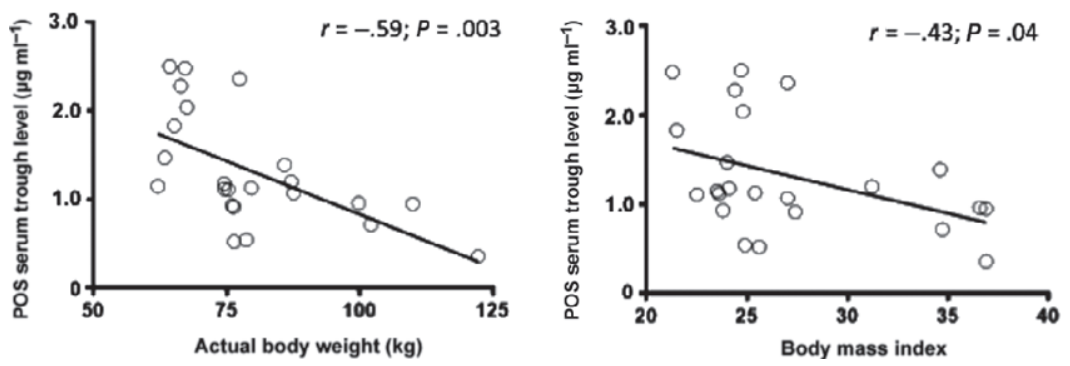

with those who weighed $<90 \mathrm{~kg}\left(1.43 \pm 0.14 \mu \mathrm{g} \mathrm{ml}^{-1}\right)$ $(P=0.006)$. In patients without diarrhoea, mean posaconazole trough levels were lower in patients with $\mathrm{BMI} \geq 30 \quad\left(0.93 \pm 0.15 \mu \mathrm{g} \mathrm{ml}^{-1}\right) \quad$ compared with BMI $<30\left(1.45 \pm 0.16 \mu \mathrm{g} \mathrm{ml}^{-1}\right),(P=0.03)($ Fig. 1b).

Scatterplots presented in Fig. 2 summarise the distribution of body weight and BMI in the patient population and the relationship with posaconazole serum trough levels. Patients who had higher body weight $(\geq 90 \mathrm{~kg})$ and higher BMI $(\geq 30)$ had lower posaconazole serum trough levels (correlation coefficient $r=-0.4$, $P=0.035$ and $r=-0.3, \quad P=0.15$ respectively) (Fig. 2a). This correlation achieved greater significance when patients with diarrhoea were excluded from the analysis (correlation coefficient $r=-0.59, P=0.003$ and $r=-0.43, P=0.04$ respectively) (Fig. $2 b$ ).

\section{Discussion}

This report describes our experience using delayed release posaconazole tablets for prophylaxis in highrisk patients. Our findings suggest that this formulation overcomes some of the expected variation in serum trough levels that has been seen with posaconazole solution.

Therapeutic drug monitoring of serum concentrations is a surrogate for assessing patient exposure and drug efficacy in the clinical setting. ${ }^{9}$ Although data are conflicting, in clinical practice a target posaconazole trough concentration of $\geq 0.7 \mu \mathrm{g} \mathrm{ml}^{-1}$ is used for the prevention of invasive fungal infections. , $^{5,10,12-14}$ In our study, the majority $(>70 \%)$ of patients attained serum trough concentrations $\geq 0.7 \mu \mathrm{g} \mathrm{ml}^{-1}$. However, patients with BMI $\geq 30$ or actual body weight $\geq 90 \mathrm{~kg}$ were more likely to have suboptimal levels.

A cutoff of below and above $90 \mathrm{~kg}$ actual body weight was chosen in this study as it was our anecdotal clinical observation that patients above this threshold attained lower posaconazole serum concentrations. Indeed, it was this observation that led us to conduct the present study. Similarly, we used BMI cutoff of below and above 30 based on the World Health Organization's definition for obesity. ${ }^{15}$ Pathophysiological changes seen in patients with higher BMI, such as changes in blood volume, cardiac output, volume of distribution, protein binding, and hepatic metabolism, may alter the pharmacokinetics of posaconazole. ${ }^{16,17}$ Furthermore, we speculate that as posaconazole is a lipophilic antifungal agent, it may distribute into the excess adipose tissue of obese patients leaving less drug available in the serum. ${ }^{18}$ Lastly, posaconazole is metabolised via glucuronidation, which is increased in obesity, potentially leading to increased metabolism, elimination, and decreased exposure of posaconazole. ${ }^{16}$ Interestingly, in our study, the coefficient of correlation was higher for the body weight than the BMI. As the BMI is a function of body weight and height, it is possible that patient body weight is the attributable variable for the trough concentration. This may be a reflection of the limitations of BMI. Indeed, BMI is 
truly a measure of excess weight, rather than excess adiposity. Age, sex, muscle mass can all skew the accuracy of BMI. Whether total body weight, BMI or both are relevant covariates for posaconazole serum levels needs further investigation.

Patients with diarrhoea manifested suboptimal trough concentrations. We speculate that lower trough levels observed in these patients could be due to gastrointestinal disruption and an increase in gastric emptying, both resulting in less absorption.

Our study has several limitations. We studied a small number of patients from a single centre. Ideally tissue and not serum concentrations would have given a better indication of posaconazole pharmacokinetics. ${ }^{19}$ From this study, it is not known whether obese patients attain high tissue concentrations despite lower serum levels.

Clinicians should consider therapeutic drug monitoring when using posaconazole, particularly in patients with higher weight and BMI and those with diarrhoea. Further studies are necessary to determine the optimal dosing regimen in these patients.

\section{Acknowledgments}

We thank Dr. Jose A. Diaz from the University of Michigan for his help with the statistical analysis of our data.

\section{Conflict of interests}

Dr. Daniel Couriel serves as a member of the Medical Advisory Board for Merck, Sharp and Dohme Corporation. He also receives research funding from Therakos, Inc. All other authors have no conflict of interest to report.

\section{References}

1 Marr KA, Carter RA, Crippa F, Wald A, Corey L. Epidemiology and outcome of mould infections in hematopoietic stem cell transplant recipients. Clin Infect Dis 2002; 34: 909-17.

2 Rotstein C, Bow EJ, Laverdiere M, Ioannou S, Carr D, Moghaddam N. Randomized placebo-controlled trial of fluconazole prophylaxis for neutropenic cancer patients: benefit based on purpose and intensity of cytotoxic therapy. The Canadian Fluconazole Prophylaxis Study Group. Clin Infect Dis 1999; 28: 331-40.
3 Cornely OA, Maertens J, Winston DJ, Perfect J, Ullmann AJ, Walsh TJ, et al. Posaconazole vs. fluconazole or itraconazole prophylaxis in patients with neutropenia. New Engl J Med 2007; 356:348-59.

4 Ullmann AJ, Lipton JH, Vesole DH, Chandrasekar P, Langston A, Tarantolo SR, et al. Posaconazole or fluconazole for prophylaxis in severe graft-versus-host disease. New Engl J Med 2007; 356: 335-47.

5 Dolton MJ, Ray JE, Chen SC, Ng K, Pont L, McLachlan AJ. Multicenter study of posaconazole therapeutic drug monitoring: exposureresponse relationship and factors affecting concentration. Antimicrob Agents Chemother 2012; 56: 5503-10.

6 Krishna G, Ma L, Martinho M, Preston RA, O'Mara E. A new solid oral tablet formulation of posaconazole: a randomized clinical trial to investigate rising single- and multiple-dose pharmacokinetics and safety in healthy volunteers. J Antimicrob Chemother 2012; 67: 2725-30.

7 FDA. FDA approves Posaconazole delayed release tablets, 2013. http://www.accessdata.fda.gov/drugsatfda_docs/label/2013/ 205053s000lbl.pdf [Accessed 2014 October 12, 2014].

8 Duarte RF, Lopez-Jimenez J, Cornely OA, Laverdiere M, Helfgott D, Haider S, et al. Phase $1 \mathrm{~b}$ study of new posaconazole tablet for prevention of invasive fungal infections in high-risk patients with neutropenia. Antimicrob Agents Chemother 2014; 58: 5758-65.

9 Dolton MJ, Ray JE, Marriott D, McLachlan AJ. Posaconazole exposure-response relationship: evaluating the utility of therapeutic drug monitoring. Antimicrob Agents Chemother 2012; 56: 2806-13.

10 Jang SH, Colangelo PM, Gobburu JVS. Exposure-response of posaconazole used for prophylaxis against invasive fungal infections: evaluating the need to adjust doses based on drug concentrations in plasma. Clin Pharmacol Ther 2010; 88: 115-9.

11 Common Terminology Criteria for Adverse Events (CTCAE) Version 4.0. http://www.evs.nci.nih.gov/ftp1/CTCAE/CTCAE_4.03_2010-0614_QuickReference_5x7.pdf [Accessed on 26 February 2015].

12 Tonini J, Thiebaut A, Jourdil JF, Berruyer AS, Bulabois CE, Cahn JY, et al. Therapeutic drug monitoring of posaconazole in allogeneic hematopoietic stem cell transplantation patients who develop gastrointestinal graft-versus-host disease. Antimicrob Agents Chemother 2012; 56: 5247-52.

13 Eiden C, Meniane JC, Peyriere H, Eymard-Duvernay S, Le Falher G, Ceballos $\mathrm{P}$, et al. Therapeutic drug monitoring of posaconazole in hematology adults under posaconazole prophylaxis: influence of food intake. Eur J Clin Microbiol Infect Dis 2012; 31: 161-7.

14 Gross BN, Ihorst G, Jung M, Wasch R, Engelhardt M. Posaconazole therapeutic drug monitoring in the real-life setting: a single-center experience and review of the literature. Pharmacotherapy 2013; 33: $1117-25$.

15 World Health Organization. Obesity and overweight. http://www. who.int/mediacentre/factsheets/fs311/en [Accessed on 26 February 2015].

16 Hanley MJ, Abernethy DR, Greenblatt DJ. Effect of obesity on the pharmacokinetics of drugs in humans. Clin Pharmacokinet 2010; 49: $71-87$.

17 Wurtz R, Itokazu G, Rodvold K. Antimicrobial dosing in obese patients. Clin Infect Dis 1997; 25: 112-8.

18 Li Y, Theuretzbacher U, Clancy CJ, Nguyen MH, Derendorf H. Pharmacokinetic/ pharmacodynamic profile of posaconazole. Clin Pharmacokinet 2010; 49: 379-96.

19 Felton T, Troke PF, Hope WW. Tissue penetration of antifungal agents. Clin Microbiol Rev 2014; 27: 68-88. 